\title{
BASIC AND CLINICAL INSIGHTS IN CATECHOLAMINERGIC (FAMILIAL) POLYMORPHIC VENTRICULAR TACHYCARDIA
}

\author{
Manlio F. Márquez ${ }^{1 *}$, Armando Totomoch-Serra ${ }^{2}$, Angélica Rueda ${ }^{3}$, José E. Avelino-Cruz ${ }^{4}$, \\ AND ANTONIO GALLEGOS-CORTEZ ${ }^{5}$ \\ Departments of ${ }^{1}$ Electrocardiology, Instituto Nacional de Cardiología "Ignacio Chávez," Mexico City; ${ }^{2}$ Genetics \\ and Molecular Biology, and ${ }^{3}$ Biochemistry, Centro de Investigación y de Estudios Avanzados, Instituto Politécnico \\ Nacional, Mexico City; ${ }^{4}$ Laboratory of Molecular Cardiology, Institute of Physiology, Benemérita Universidad \\ Autónoma de Puebla, Puebla; ${ }^{5}$ Department of Electrophysiology, Hospital de Alta Especialidad del Bajío, León, \\ Guanajuato, Mexico.
}

\begin{abstract}
Catecholaminergic polymorphic ventricular tachycardia (CPVT) is a potentially lethal disease, whose characteristic ventricular tachycardias are adrenergic-dependent. Although rare, CPVT should be considered in the differential diagnosis of young individuals with exercise-induced syncope. Mutations in five different genes (RYR2, CASQ2, CALM1, TRDN, and TECRL) are associated with the CPVT phenotype, although RYR2 missense mutations are implicated in up to $60 \%$ of all CPVT cases. Genetic testing has an essential role in the diagnosis, management, pre-symptomatic diagnosis, counseling, and treatment of the proband; furthermore, genetic information can be useful for offspring and relatives. By expert consensus, CPVT gene testing is a Class I recommendation for patients with suspected CPVT. Beta-adrenergic and calcium-channel blockers are the cornerstones of treatment due to the catecholaminergic dependence of the arrhythmias. Unresponsive patients are treated with an implantable cardioverter-defibrillator to reduce the risk of sudden cardiac death. In the present article, a brief review of the genetic and molecular mechanisms of this intriguing disease is provided. (REV INVEST CLIN. 2019;71:226-36)
\end{abstract}

Key words: Sudden cardiac death. Syncope. Exercise. Catecholaminergic polymorphic ventricular tachycardia. Genetic testing. Beta-blockers. Calcium channel blockers.

Corresponding author:

*Manlio F. Márquez

Departamento de Electrocardiografía

Instituto Nacional de Cardiología Ignacio Chávez

Juan Badiano, 1

Col. Sección XVI

C.P. 14080, Mexico City, Mexico

Received for publication: 06-12-2018

E-mail: manlio.marquez@gmail.com

Approved for publication: 05-03-2019

DOI: $10.24875 / R I C .19002939$ 


\section{INTRODUCTION}

In the medical literature of the $20^{\text {th }}$ century, there are isolated cases of patients reported with clinical and electrocardiographic (ECG) characteristics of what is now known as catecholaminergic polymorphic ventricular tachycardia (CPVT);1,2 nevertheless, it was not until 1975 that Reid et $\mathrm{al}^{3}$. reported a typical case of the disease. They presented a young girl (6-yearold) without cardiac structural abnormality, with bidirectional ventricular tachycardia precipitated by effort and emotional stress. However, Coumel et al. were the first to gather a case series and introduce the term "catecholamine-induced" 4 . With this cumulative series ( 4 cases of their own and 10 more from the literature) they provided the basis to consider CPVT as an independent entity. Almost 20 years later, in 1995, the same French group ${ }^{5}$ enlarged their series to 21 patients and could characterize the arrhythmia as "consisting of isolated polymorphic ventricular extrasystoles followed by salvoes of bidirectional and polymorphic tachycardia susceptible to degeneration into ventricular fibrillation (VF)." Again, its reproducibility by any form of increasing adrenergic stimulation, as previously known, was a common denominator. As there was a familial history of syncope or sudden death in $30 \%$ of the patients, some groups named the disease as "familial polymorphic ventricular tachycardia." $\beta$-blocker therapy usually resulted in control of symptoms and tachyarrhythmias; further developments of syncopal events or unexpected deaths were attributed to treatment interruption. It was not until 2001 that Priori et $\mathrm{al}^{6}$. and Laitinen et $\mathrm{al}^{7}$. provide us with a better understanding of the molecular pathogenic mechanism through the study of the isoform two of the intracellular $\mathrm{Ca}^{2+}$ channel/ryanodine receptor ( $R Y R 2$ ), which is the major cellular mediator of a calcium-induced calcium release (CICR) mechanism in animal cells. Although mutations in five different genes (RYR2, CASQ2, CALM1, TRDN, and TECRL) are associated with CPVT phenotype, RYR2 missense mutations are implicated in up to $60 \%$ of all CPVT cases $^{8,9}$.

In Mexico, a recent estimate reports a prevalence of 9.5/1000 patients/year for sudden death in children $^{10}$; unfortunately, there is no specific data in the country for the prevalence of CPVT in children. On the other hand, CPVT is estimated in $1 / 10,000^{11}$ with sudden death as the first presentation in $<30 \%$ of the cases $^{12}$. This review highlights insights from clinical, molecular, and genetic features of CPVT.

\section{CLINICAL DIAGNOSIS}

Diagnosis of CPVT must be suspected in individuals, especially children, with exercise- or emotion-induced syncope $^{13}$. Affected subjects may have a family history of sudden juvenile death or stress-induced syncope $^{5}$, although this is not a rule ${ }^{14}$. Patients may present life-threatening VT or VF during emotional or physical stress, with exercise-related syncope; even sudden cardiac death could be the first manifestation of the disease ${ }^{13,14}$. The diagnosis could be so difficult that in the series of 21 patients described by Leenhardt et al., near half of the children were initially considered with epilepsy and treated with anticonvulsants for several months and in some cases, years ${ }^{5}$.

In the most-recent registry of 27 pediatric centers, including 226 patients evaluated as part of the family screening, $78 \%$ presented with symptoms, and $19 \%$ were asymptomatic. Syncope was the most frequent presentation occurring in $64 \%$, followed by nonfatal cardiac arrest in 33\%, palpitations in $7 \%$, and chest pain in $4 \%$. The median age of onset of symptoms was 10.8 years (6.8-13.2). As previously mentioned, in $38 \%$ of patients there was a delay in the diagnosis for more than 1 year, and $56 \%$ of children initially received a misdiagnosis ${ }^{15}$.

Two main ECG types of polymorphic VT have been described ${ }^{16}$, the polymorphic VT and the bidirectional tachycardia (with electrical alternans of QRS). Typically, the arrhythmia begins above a heart rate threshold of 120-130 bpm, initially with isolated monomorphic and then polymorphic ventricular extrasystoles; if the activity is stopped, the arrhythmia disappears without clinical consequences. If the effort continues, PVC is followed by salvoes of bidirectional and then polymorphic VT (350-400 bpm) susceptible to degeneration into $\mathrm{VF}^{5}$.

To exemplify the clinical variability of CPVT, the following examples are relevant. In a case series where 14 of the 30 probands had RYR 2 mutations, the affected patients had events at a younger age (first syncope at 8 vs. 20 years), and male sex was a significant risk factor for syncope compared to those 
Figure 1. Cardiac excitation-contraction coupling. Schematic representation of a T-tubule in a ventricular cardiomyocyte. Ca ${ }^{2+}$, calcium in its ionic form; DHRP, dihydropyridine receptor or L-type $\mathrm{Ca}^{2+}$ channel; $\mathrm{Na}-\mathrm{CaX}$, sodium/calcium exchanger; PLB, phospholamban; SERCA, sarco/endoplasmic reticulum $\mathrm{Ca}^{2+}$ pump; $\mathrm{RyR}$, ryanodine receptor; $\mathrm{H}^{+}$, proton gradient in mitochondria.

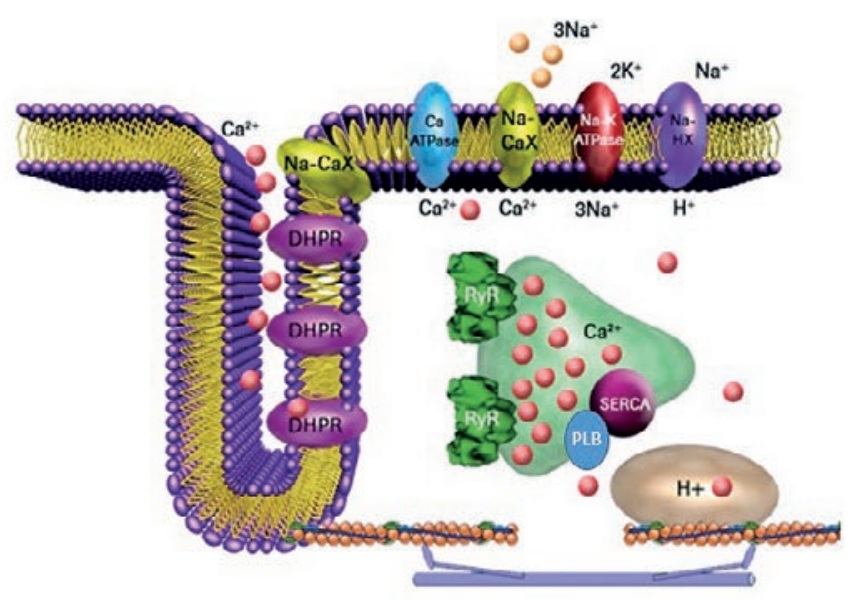

without such mutations. In contrast, $90 \%$ of the subjects without an RYR2 mutation were female. The arrhythmias documented in those 14 patients were bidirectional VT in $36 \%$, polymorphic VT in $58 \%$, and catecholaminergic idiopathic $V F$ in $50 \%{ }^{13}$. In the case of genomic deletion in RYR2 and polymorphic VT, other clinical manifestations have been observed including sinoatrial node and atrioventricular node dysfunction, atrial fibrillation, and dilated cardiomyopathy ${ }^{17}$. In a second genetic form of CPVT, due to mutations in CASQ2, the first seven affected families included children who died suddenly at an average age of 7 years and 12 of 41 family members with a history of recurrent syncope or seizures beginning at 6 years of age. All the 12 symptomatic patients had relative resting bradycardia and presented polymorphic VT induced by exercise ${ }^{18}$.

\section{Involvement of RYR2 Missense Mutations in the Arrhythmogenic CPVT Disorder}

Calcium in ionic form $\left(\mathrm{Ca}^{2+}\right)$ is an essential and intracellular messenger of cardiac contractile cells (cardiomyocytes) due to its significant participation in several cellular processes, including gene expression, cell differentiation, apoptosis, and cell contraction; the latter was stated for the first time by Sidney Ringer ${ }^{19}$. Periodic fluctuations in the intracellular $\mathrm{Ca}^{2+}$ concentration $\left(\left[\mathrm{Ca}^{2+}\right] \mathrm{i}\right)$ of cardiomyocytes control the magnitude and duration of contractile force developed by the cardiac cells ${ }^{20}$. Under physiological conditions, cardiomyocytes translate action potentials into mechanic force through the excitation-contraction coupling (ECC) mechanism. In the ECC, the sarcolemma depolarization activates voltage-dependent L-type $\mathrm{Ca}^{2+}$ channels. Located at the T-tubules, they induce an inward $\mathrm{Ca}^{2+}$ current $(\mathrm{ICa})$ that, in turn, elicits the release of more $\mathrm{Ca}^{2+}$ through the aperture of clusters of RyRs, through the CICR mechanism ${ }^{20}$ (Fig. 1). Hence, the RyR2 has a key role in the ECC as the cation channel responsible for the massive release of $\mathrm{Ca}^{2+}$ from the sarcoplasmic reticulum (SR) in the cardiac systole.

However, it is recognized that RyRs are not entirely closed during the relaxation phase of the cardiac cycle. In diastole, the RyRs release $\mathrm{Ca}^{2+}$ in several forms - mainly as $\mathrm{Ca}^{2+}$ sparks, $\mathrm{Ca}^{2+}$ wavelet, and $\mathrm{Ca}^{2+}$ waves - giving basis to a diastolic $\mathrm{Ca}^{2+}$ leak. In physiological conditions, RyRs participate in the regulation of SR $\mathrm{Ca}^{2+}$ load ${ }^{21-24}$. However, under pathological conditions, abnormal diastolic $\mathrm{Ca}^{2+}$ leak through RyR2 participates in the generation of both acquired and hereditary arrhythmias, such as CPVT ${ }^{25}$.

Although the gene that codifies for RyR2 has only one copy in the human genome - located in chromosome 1 , locus $1 q 43^{26}$ - it contains 105 exons and is considered one of the largest genes found in our genome ${ }^{27}$. With 4967 residues per monomer, the functional hRYR2 (homotetramer) is the largest ion 
Figure 2. Localization of catecholaminergic polymorphic ventricular tachycardia (CPVT) hotspots in RYR2 structural domains. Linear representation of structural domains identified in the RYR2 monomer. The domain boundaries are assigned according to Peng et $\mathrm{a}^{29}$. The four CPVT1 hotspots (CPVT1-I to -IV) are depicted above the domains. NTD, N-terminal domain; SPRY1-3, P1, and P2 domains; Handle, Handle domain; HD1-2, helical domains 1 and 2; U, U motif; CD, channel domain. Scheme prepared with IBS illustrator ${ }^{84}$.

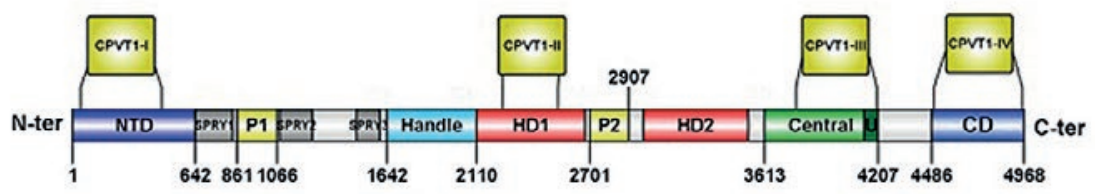

channel currently known. Since 2001, more than 150 RyR missense mutations have been associated with the CPVT phenotype (human gene mutation database; http://www.hgmd.cf.ac.uk/ac/index.php). The RyR2 isoforms are originated by missense mutations occurring mainly at four hotspots: N-terminal (CPVT1-I, RyR2 residues: 62-466); central (CPVT1-II, RyR2 residues: 2246-2534), C-terminal (now CPVT1-IV, RyR2 residues: 4497-4959), and the recently defined hotspot-3 (CPVT1-III, RyR2 residues: 3778-4201)28. Due to the lately described near-atomic resolutions of the RyR2 from the porcine heart in its open and closed conformations $^{29}$, it is possible to locate these CPVT hotspots into distinct structural domains (Fig. 2). For instance, the CPVT1-I is in the $\mathrm{N}$-terminal domain of the protein. The CPVT1-II is delimited inside the HD1 domain. The CPVT1-III, even though it is absent in the RyR1 isoform, encompasses the central domain and the U motif of RyR2. Finally, the CPVT1-IV hotspot is in the channel domain. Mutations occurring in CPVT1-III hotspot are currently of relevant interest due to their localization at the central domain of the RyR2 (Fig. 3). The central domain serves as the primary transducer that integrates and translates the conformational changes of the cytoplasmic domains to channel gating ${ }^{28}$, evidencing that alterations in intracellular $\mathrm{Ca}^{2+}$ handling are involved in the generation of arrhythmias $^{8,30}$. Furthermore, mutations at CPTV1-III and -IV may also have a profound impact on the cytosolic $\mathrm{Ca}^{2+}$ activation of RyR2, and on the actions of modulators such as caffeine and ATP, since they could be in the boundaries of binding sites for these ligands (Fig. 3 ).

Only a few numbers of RyR 2 variants have been characterized at the molecular level; most of them generate ion channels with a gain-of-function that lead to out of control diastolic $\mathrm{Ca}^{2+}$ leak ${ }^{27,31}$. The pathological consequence of an augmented diastolic $\mathrm{Ca}^{2+}$ leak is that it would activate the $\mathrm{Na}^{+} / \mathrm{Ca}^{2+}$ exchanger generating a net inward current that is causative of delayed afterdepolarizations (DADs), triggering additional RyR2 activation, and aftercontractions ${ }^{32}$.

One of the first RyR2 point mutations related to a dominant form of CPVT was R4496C 6,33 and a knockin transgenic mouse harboring this mutation was generated $^{34}$. The mice presented an arrhythmogenic phenotype very similar to the clinical manifestations of patients carrying the RyR ${ }^{R 4497 C}$ including the presence of bidirectional VT. Furthermore, after challenging the Ry $R^{R 4497 C}$ cardiomyocytes with both adrenaline and caffeine, the cells show DADs, suggesting that $\mathrm{Ca}^{2+}$ dependent arrhythmias are elicited by $\beta$-adrenergic activation. Intact quiescent RyR ${ }^{R 4497 C}$ cardiomyocytes exhibit increased occurrence of $\mathrm{Ca}^{2+}$ sparks and $\mathrm{Ca}^{2+}$ waves indicative of an abnormal diastolic $\mathrm{Ca}^{2+}$ leak. This augmented $\mathrm{Ca}^{2+}$ release is further enhanced by $\beta$-adrenergic stimulation and increasing frequency, similarly to what happens in humans with $\mathrm{CPVT}^{35}$.

This scheme is adequate for most RyR2-linked CPVT mutations. However, in 2002, Priori et al. also reported a special RyR2-A4860G mutation ${ }^{12}$. When the recombinant RyR2-A4860G channels were expressed in HEK293cells, one striking feature of the RyR2A4860G channels was the loss of luminal $\mathrm{Ca}^{2+}$ sensitivity that generates loss-of-function channels ${ }^{36}$; then the question was, how do hypoactive channels participate in cardiac arrhythmias? Thus, the group of Valdivia et al. generated a transgenic mouse harboring the RyR2-A4860G channel with loss-of-function that exhibited basal bradycardia, but after sympathetic stimulation, the mice developed malignant arrhythmias ${ }^{37}$. At a single-cell level, the loss-of-function mutations are related to diminished $\mathrm{Ca}^{2+}$ activation and progressive SR Ca ${ }^{2+}$ overload $^{9,38}$ that may 
Figure 3. Representation of two RyR monomers bound with four different ligands: Ca ${ }^{2+}$ (green balls), $\mathrm{Zn}^{2+}$ (gray balls), ATP and caffeine, (PDB accession code 5TAL). The red circles highlight the Central and Channel Domain of the RyR where the ligands and most of the catecholaminergic polymorphic ventricular tachycardia 1-III and -IV mutations are found.

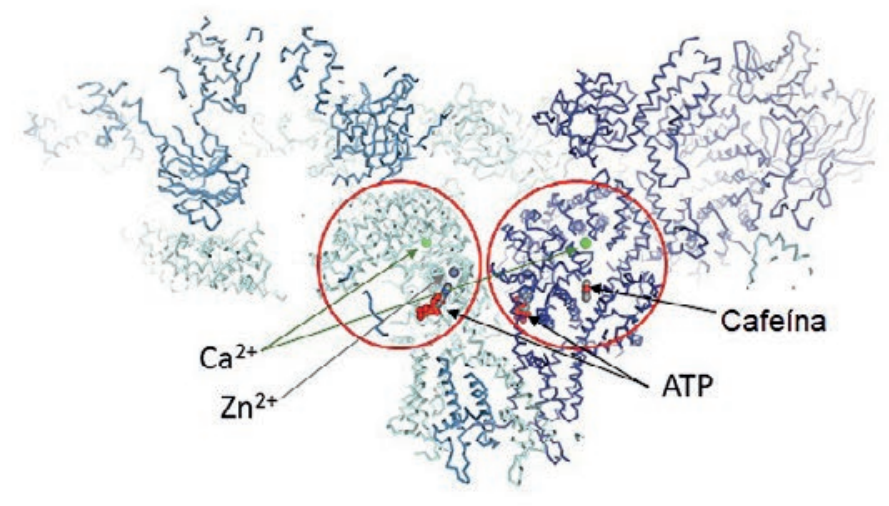

lead to abnormal SR $\mathrm{Ca}^{2+}$ release and subsequent activation of NCX. Other examples of these mutations are $14855 \mathrm{M}, \mathrm{S} 4938 \mathrm{~F}$, and $\mathrm{E} 4872 \mathrm{Q}^{38,39}$. Interestingly, all of these mutations are located mainly on the channel domain where the $\mathrm{Ca}^{2+}$ binding site is situated $^{40}$ (Fig. 3).

These novel findings have profound therapeutic implications since CPVT treatment should not assume that CPVT-linked RyR2 mutations produce gain-offunction channels only; thus, future work should also focus on developing more suitable therapeutic interventions for patients with arrhythmias associated to loss-of-function channels.

\section{Mechanisms of Arrhythmogenesis in Other Affected Genes: calsequestrin, Calmodulin, and Triadin}

ECC mechanism relies on the right arrangement of the dyads and the synchronous activity of the $\mathrm{Ca}^{2+}$ release unit (CRU) proteins; during this process, the opening of RyR2 will allow the massive $\mathrm{Ca}^{2+}$ release from the SR, the increase in the free cytoplasmic $\mathrm{Ca}^{2+}$ and the cellular contraction. At the luminal side, the RyR2 is tightly regulated by some proteins that directly interact with it and modify its $\mathrm{Ca}^{2+}$ sensitivity and its kinetics. These proteins, named calsequestrin (CASQ), triadin (TRD), junctin, and HRC, are critical regulators of RyR2 and endow the channel with an excellent fine tuning ${ }^{41,42}$. At the cytosolic side, at least seven different accessory proteins bind the receptor, but we will mention only calmodulin (CALM).
Any alterations to these proteins will be translated into functional changes in the $\mathrm{Ca}^{2+}$ regulatory machinery and finally in an alteration in the intracellular $\mathrm{Ca}^{2+}$ homeostasis.

About these proteins related to CPVT, there are at least 14 mutations in the gene encoding for cardiac calsequestrin (http://triad.fsm.it/cardmoc/), 3 in the gene encoding for triadin ${ }^{43}$, and 3 more for calmodu$\operatorname{lin}^{44,45}$. These mutations will result in an altered structure of the protein by a) modifying its $\mathrm{Ca}^{2+}$ binding properties, as occurs with CALM1 A53I and A97S or CALM3 A103V mutants ${ }^{42}$ or with the CASQ2 R33Q ${ }^{46}$; b) making the protein readily degradable as CASQ2 R33Q or TRD T59R ${ }^{43,45,47}$; or C) decreasing its expression by producing a non-functional protein due to the presence of premature stop codons ${ }^{47,48}$. Independent of the mechanism, the $\mathrm{Ca}^{2+}$ release from SR is altered thus inducing the CPVT phenotype.

CPVT has been considered a cardiomyopathy with no structural heart alterations; however, in 2006, Knollman et al. engineered a CPVT2 animal model, the CASQ2-null mouse, and demonstrated for the $1^{\text {st }}$ time that anatomical heart abnormalities in CPVT are not evident, since structural changes are inside cardiomyocytes, in the structure of the dyads, specifically in the junctional $\mathrm{SR}^{49}$. In experiments performed in CPVT2 animal models, the absence or decrease in expression of calsequestrin induces ultrastructure alterations of the heart, namely disarray on the coupon due to an increase in the widening of the JSR, a decrease in the number of coupons, and increase in the 
JSR volume ${ }^{46,49,50}$. The ultrastructural abnormalities can be long-lasting and reversed if exogenous Casq2 is expressed in the cardiac cells $s^{50,51}$. Similar results were obtained in the Triadin null mouse, where it was also demonstrated that the absence of triadin decreases the extent of JSR by reducing the length and number of contacts between JSR and T tubules; furthermore, the Cav1.2 channels juxtaposed to RyR2 and the colocalization between CASQ2 and RyR2 were decreased without changes in the expression of Cav1.2 $2^{52,53}$.

Interestingly, the absence of TRD or CASQ2 is accompanied by a decrease in expression of CASQ2 or TRD, respectively $46,49,50,52$. Furthermore, other CRU proteins such as RYR2, junctin or junctophilin 2 are also downregulated or upregulated in some animal models ${ }^{54}$. These experiments highlight, first, the crucial role of triadin and calsequestrin in maintaining the architecture of the dyad and the effectiveness of the ECC and second, the fact that both proteins are vital for the heart function.

Regarding calmodulin, in 2012 Nyegaard et al., reported two missense mutations in CALM1. The N531 was found in a Swedish family with the dominant form of CPVT-like arrhythmias, while the other mutant, N97S, was identified in an Iraqi-origin woman diagnosed with $\mathrm{CPVT}^{4} 4$. A third mutation, A103V, this time in the isoform 3 of CALM, was found in a woman clinically diagnosed with $\mathrm{CPVT}^{45}$. The three mutations lead to altered calcium binding properties of calmodulin, and only the CALM1 A97S also showed a deficient interaction with the RYR2 calmodulin binding domain at low calcium concentration $(<100 \mathrm{nM})^{44}$. In vitro, functional evaluation revealed that all the mutants promoted calcium sparks and a decrease in the SR calcium content. CALM1 N97S and CALM3 A103V also decreased the calcium-dependent inactivation of Cav1.2 with no significant effects on the action potential morphology ${ }^{45}$.

Finally, the animal models of CPVT in which the effect of several mutant proteins has been characterized, have advanced the knowledge on the pathophysiology of CPVT, i.e., (1) the widening of JSR is a compensatory response to the decreased capacity of CASQ2 in the SR to store calcium. (2) A disarray in JSR around $T$ tubules directly affects the coupons and the effectiveness in communication between voltage-gated calcium channels in the plasma membrane and RYR2 in the SR membrane, therefore, affecting downstream the entire ECC. (3) Since triadin and junctin work in binding CASQ2 to ryanodine receptor, the altered interaction between these proteins will decrease the RyR2-calcium modulation, inducing calcium leakage from JSR. (4) CALM binding to RyR2 decreases the open probability of the channel, and a decrease in the calmodulin sensitivity to calcium or a defective interaction with the RyR2 could induce a leaky ryanodine receptor by increasing opening conformation of the channel. (5) Continuous SR calcium leakage increases the risk of spontaneous calcium release and CPVT.

\section{Involvement of TECRL Protein in CPVT}

The trans-2,3-enoyl-CoA reductase-like (TECRL) protein does not have a direct effect on the cardiac phenotype, although pluripotent stem cell-derived cardiomyocytes have been shown to have a participation in the action potential duration. In addition, it has been observed that knocking of TECRL induces a decrease of RyR2 and CASQ2 ${ }^{55}$. This gene has recently been located in 4q13.1 locus, has 12 exons, and spans 134 $\mathrm{kb}$ (online mendelian inheritance in man [OMIM], http://omim.org/entry/617242). Two studies have reported a mutation in one of six affected children carrying a homozygous splice site mutation c. $331+1 \mathrm{G}$ $>\mathrm{A}^{56}$ and, in two French-Canadian women, a homozygous mutation R196Q ${ }^{55}$.

\section{Genetic Testing}

Genetic testing has an essential role in diagnosis, management, pre-symptomatic diagnosis, counseling and treatment of the proband, and in some cases the information obtained can be useful for offspring and relatives ${ }^{57,58}$. In CPVT, there are five genes identified with point mutations or deletions associated to CPVT phenotype ${ }^{7,33,43,44,47,48,59,60}$, being $R Y R 2^{33,59}, \mathrm{CALM1}^{44}, \mathrm{TRDN}^{47}$, and CASQ ${ }^{60}$ the affected genes. In this group, the gene with most mutations related to CPVT is RYR2, and together the five genes can explain $60 \%$ of cases of CPVT in patients with recessive or dominant inheritance, failing to account for $40 \%$ of cases with CPVT ${ }^{61}$. The increase in association between genes affected in CPVT has made genetic screening part of the tools for risk stratification in cardiogenetic diseases. At present, there are five molecular types described in 
Table 1. Molecular classification of CPVT by OMIM*.

\begin{tabular}{|c|c|c|c|c|c|}
\hline Type & $\begin{array}{l}\text { Mendelian } \\
\text { pattern }\end{array}$ & Gene & Locus & $\begin{array}{l}\text { Most common } \\
\text { clinical data }\end{array}$ & Miscellaneous \\
\hline $\begin{array}{l}\text { CPVT Type } 1 \\
\text { OMIM } \\
\quad(\# 604772)\end{array}$ & $\begin{array}{l}\text { Autosomal } \\
\text { Dominant }\end{array}$ & RYR2 & $1 q 43$ & $\begin{array}{l}\text { Polymorphic ventricular } \\
\text { tachycardia induced by } \\
\text { physical activity, stress, } \\
\text { or catecholamine infusion, } \\
\text { syncope, sudden death }\end{array}$ & $\begin{array}{l}\text { Sinoatrial node dysfunction, } \\
\text { atrioventricular node } \\
\text { dysfunction, atrial } \\
\text { fibrillation, atrial standstill } \\
\text { left ventricular dysfunction } \\
\text { left ventricular dilation, } \\
\text { seizures }\end{array}$ \\
\hline $\begin{array}{l}\text { CPVT Type } 2 \\
\text { OMIM } \\
\quad(\# 611938)\end{array}$ & $\begin{array}{r}\text { Autosomal } \\
\text { Recessive }\end{array}$ & CASQ2 & 1P13.1 & $\begin{array}{l}\text { Polymorphic ventricular } \\
\text { tachycardia induced by } \\
\text { physical activity, stress, } \\
\text { or catecholamine infusion, } \\
\text { bradycardia, relative resting, } \\
\text { syncope, sudden death }\end{array}$ & Seizures \\
\hline $\begin{array}{l}\text { CPVT Type } 3 \\
\text { OMIM } \\
(\# 614021)\end{array}$ & $\begin{array}{l}\text { Autosomal } \\
\text { Recessive } \\
\text { (consanguineous } \\
\text { family) }\end{array}$ & $\begin{array}{l}\text { Marker } \\
\text { D7S493 } \\
\text { (TECRL) }\end{array}$ & $7 p 22-p 14$ & $\begin{array}{l}\text { Polymorphic ventricular } \\
\text { tachycardia induced by } \\
\text { physical activity, borderline } \\
\text { prolonged QT interval, } \\
\text { syncope, sudden death }\end{array}$ & $\begin{array}{l}\text { Onset at an early age, } \\
\text { associated with sudden } \\
\text { death in childhood }\end{array}$ \\
\hline $\begin{array}{l}\text { CPVT Type } 4 \\
\text { OMIM } \\
(\# 614916)\end{array}$ & $\begin{array}{r}\text { Autosomal } \\
\text { dominant }\end{array}$ & CALM1 & $14 q 32.11$ & $\begin{array}{l}\text { Polymorphic ventricular } \\
\text { tachycardia induced by } \\
\text { physical activity or stress, } \\
\text { dizziness, syncope, cardiac } \\
\text { arrest, sudden death, } \\
\text { prominent U-waves in anterior } \\
\text { leads on electrocardiogram, } \\
\text { premature ventricular } \\
\text { contractions, including } \\
\text { couplets and triplets of } \\
\text { variable morphology }\end{array}$ & $\begin{array}{l}\text { Onset within the first decade } \\
\text { of life }\end{array}$ \\
\hline $\begin{array}{l}\text { CPVT Type } 5 \\
\text { OMIM } \\
(\# 61544)\end{array}$ & $\begin{array}{l}\text { Autosomal } \\
\text { recessive }\end{array}$ & TRDN & $6 q 22.31$ & $\begin{array}{l}\text { Polymorphic or bidirectional } \\
\text { ventricular extra systoles } \\
\text { polymorphic ventricular } \\
\text { tachycardia exercise-induced } \\
\text { syncope }\end{array}$ & $\begin{array}{l}\text { Proximal muscle } \\
\text { weakness, cardiac arrest, } \\
\text { and sudden death may } \\
\text { occur, even in early } \\
\text { childhood }\end{array}$ \\
\hline
\end{tabular}

*Modified from OMIM: Online Mendelian Inheritance in Man (Marla J. F. O’Neill: December 28, 2011), CPVT: catecholaminergic polymorphic ventricular tachycardia

OMIM (OMIM, http://www.omim.org) for CPVT62 (Table 1 ). Type 3 has been delimited recently by linkage of the marker D7S493, associated with the disease in one endogamic family ${ }^{56}$, and after functional studies, the affected gene was found to be TECRL; a knockout in vitro model for this gene showed a reduction of the proteins RYR2 and CASQ2 ${ }^{55,63}$. All of these five genes have diverse characteristics, for example, different sequence size, number of coding and no coding sequences, promoters, repressors, enhancers, splicing, and protein isoforms ${ }^{64}$, which could complicate the molecular study and interpretation.
Different types of techniques for DNA testing: A genetic testing, in essence, is accurate, with low cost, the results may be quickly obtained, and the technique used has a wide coverage for the affected genes. As the first option, the classical approach has been the study of selected exons, deletion/duplication analysis or direct sequence analysis based on the polymerase chain reaction ${ }^{65}$ and subsequent sanger sequencing ${ }^{66}$ (first-generation sequencing). Limiting factors of these conventional molecular techniques include low coverage, lack of amplification of large fragments or whole genes in a single assay, and also are time consuming; due to the genetic heterogeneity 
(five genes are identified). A recent solution is the use of massive parallel sequencing (Second-generation sequencing), where millions of small copies of DNA fragments are simultaneously amplified and sequenced. There are different variants of massive parallel sequencing, but together they are also known as next-generation sequencing (NGS). Due to the high coverage of NGS and the genetic heterogeneity in CPVT, different companies have developed sequencing panels including part of or all the five genes described for CPVT. An alternative to gene panels, in negative cases there is the possibility to study the suspected case through whole genome sequencing or whole exome sequencing (WES) ${ }^{61}$. In WES, the sequenced bases cover $1 \%$ of the genome, and this percentage belongs to all the coding sequences in an individual; with both techniques, new mutations related to CPVT have been found. However, there could be an associated overrepresentation of a mutation in the large whole genome and exome databases; due to this, the clinical and molecular biologist must be cautious with the results, being necessary to validate in vitro, in vivo ${ }^{67}$ and supported by at least four bioinformatic analysis.

A drawback of these new techniques is the significant amount of data and the need for more sophisticated tools and mathematical modeling, as well as the obtention of unsolicited findings related to diseases other than CPVT, which implies ethical issues for patients, offspring, relatives, and the medical team, including the cardiologist and clinical geneticist $^{67,68}$.

Indications for genetic testing: the Heart Rhythm Society (HRS) in collaboration with the European Heart Rhythm Association (EHRA), elaborated a consensus statement for genetic testing in channelopathies, recommending the genetic study as Class I for RYR2 and CASQ2 for patients with a high suspicion of CPVT based on clinical, electrophysiological, and functional studies. If a mutation in an index case is found, cascade screening is recommended ${ }^{69,70}$. However, if the primary RYR2 genetic screening is negative, a phenocopy should be considered. If ectopy is present and abundant on 24-h ambulatory monitoring and prominent $U$ wave, it is mandatory to consider KCNJ2 testing for Andersen-Tawil Syndrome ${ }^{69}$. Due to the recent discovery of TRDN ${ }^{47}, C A L M 1^{44}$, and TECRL ${ }^{55}$ genes as causes of CPVT, their inclusion in previous guidelines had not been contemplated, but we recommend screening after exclusion of RYR2 and CASQ as causes of this disease. Other genes to consider in a genetic test are $K C N J 2^{71-74}$ and $A N K B^{75}$.

\section{Treatment}

The participation in competitive sports and strenuous exercise increases the risk of ventricular arrhythmias in patients with CPVT due to the rise in catecholamines associated with exertion. As such, it is recommended that patients with CPVT avoid competitive sports ${ }^{13}$. Patients who have sustained ventricular arrhythmias are treated with an implantable cardioverter defibrillator (ICD) to terminate arrhythmias and reduce the risk of syncope and/or sudden cardiac death. However, patients should also receive medical therapy in addition to the ICD in an effort to prevent arrhythmias and minimize ICD shocks ${ }^{76}$.

$\beta$-blockers are the cornerstone of treatment due to the catecholaminergic nature of the arrhythmias. Long-acting $\beta$-blockers without intrinsic sympathomimetic activity, such as nadolol, are preferred for all patients with spontaneous or documented stressinduced ventricular arrhythmias ${ }^{77}$. Unfortunately, nadolol is not available in all countries (e.g., Mexico). In the most extensive reported series, 101 patients with CPVT followed for a mean of 7.9 years, $\beta$-blockers were administered to 81 patients (80\%) immediately after diagnosis. Of those taking a $\beta$-blocker, 62 (77\%) experienced no events during follow-up, and 9 (11\%) experienced fatal or nearfatal events. At least 4 of these 9 patients did not take their $\beta$-blocker on the day of the event ${ }^{14}$. In a systematic analysis of 11 observational studies including 403 patients with CPVT, $18.6 \%$ and $37.2 \%$ of the arrhythmic events (syncope, aborted cardiac arrest, and sudden cardiac death) occurred at 4 and 8 years, respectively ${ }^{77}$.

In patients with ongoing arrhythmias despite therapy with a $\beta$-blocker, the addition of flecainide may be useful for suppressing ventricular arrhythmias ${ }^{55,78}$. Flecainide is best known as a blocker of cardiac sodium channels. However, it also inhibits the cardiac ryanodine receptor (RYR2). In a report of two patients, the addition of flecainide prevented further episodes of CPVT; interestingly, this effect persisted 
Table 2: Expert consensus recommendations on CPVT therapeutic interventions

\begin{tabular}{|c|c|}
\hline Class I & $\begin{array}{l}\text { 1. Recommended lifestyle changes } \\
\text { a) Limit/avoid competitive sports } \\
\text { b) Limit/avoid strenuous exercise } \\
\text { c) Limit exposure to stressful environments } \\
\text { 2. B-blockers are supported in all symptomatic patients } \\
\text { 3. ICD implantation is recommended in patients who experience cardiac arrest, recurrent syncope, } \\
\text { or polymorphic/bidirectional VT despite optimal medical management, and/or LCSD }\end{array}$ \\
\hline Class Ila & $\begin{array}{l}\text { 4. Flecainide can be a useful addition to } \beta \text {-blockers in patients who experience recurrent syncope or } \\
\text { polymorphic/bidirectional VT while on } \beta \text {-blockers } \\
\text { 5. } \beta \text {-blockers can be helpful in carriers of a pathogenic CPVT mutation without clinical manifestations } \\
\text { of CPVT }\end{array}$ \\
\hline Class IIb & $\begin{array}{l}\text { 6. LCSD may be considered in patients who experience recurrent syncope or polymorphic/bidirectional VT/ } \\
\text { several appropriate ICD shocks while on } \beta \text {-blockers and in patients who are intolerant or with } \\
\text { contraindication to } \beta \text {-blockers }\end{array}$ \\
\hline Class III & $\begin{array}{l}\text { 7. ICD as a standalone therapy is not indicated in an asymptomatic patient with a diagnosis of CPVT } \\
\text { 8. Programmed electrical stimulation is not indicated in CPVT patients }\end{array}$ \\
\hline
\end{tabular}

Modified from Priori et $\mathrm{al}^{13}$. CPVT: catecholaminergic polymorphic ventricular tachycardia, ICD: implantable cardioverter defibrillator,

LCSD: left cardiac sympathetic denervation

in one patient after the withdrawal of the $\beta$-blocker and calcium channel blocker ${ }^{79}$. A subsequent series of 10 patients with CPVT type 2 who had recurrent VT despite therapy with a $\beta$-blocker (all patients) and calcium channel blockers (in 6 of 10 patients), found flecainide to be effective in suppressing exercise-induced ventricular tachyarrhythmia when given in addition to $\beta$-blockers ${ }^{80}$.

In a study of 24 patients with CPVT who underwent ICD implantation and were followed for a median of 3.3 years, 14 patients ( $58 \%$ ) received a total of 140 shocks, of which approximately $54 \%$ were felt to be adequate shocks ${ }^{81}$. Some groups propose they left cardiac sympathetic denervation (LCSD) for patients with CPVT who remain symptomatic after maximal medical therapy. Data from small case series suggest a role for LCSD in patients with CPVT ${ }^{82}$. Among the most extensive reported series, there is one of 63 CPVT patients treated with LCSD who were followed for 37 months; of 38 patients with arrhythmias while on optimal medical therapy, only $12 \mathrm{pa}-$ tients $(32 \%)$ had a recurrent arrhythmic event following $\mathrm{LCSD}^{83}$.

Recommendations from the 2013 HRS/EHRA/ APHRS expert consensus statement on the diagnosis and management of patients with inherited primary arrhythmia syndromes for the management of CPVT are summarized in Table 2.

\section{CONCLUSIONS}

CPVT is a disease that conveys a risk of sudden death in young people; therefore, its correct identification and diagnosis at an early stage can prevent fatal consequences. Although CPVT was identified since 1975 and its molecular characterization dates back to 2001 , it is only in recent years, that an increased number of cases have been genetically confirmed thanks to NGS.

\section{REFERENCES}

1. Lyon RA, Rauh LW. Extrasystoles in children. Am J Dis Child. 1939;57:278.

2. Berg KJ. Multifocal ventricular extrasystoles with adam-stokes syndrome in siblings. Am Heart J. 1960;60:966-70.

3. Reid DS, Tynan M, Braidwood L, Fitzgerald GR. Bidirectional tachycardia in a child. A study using his bundle electrography. Br Heart J. 1975;37:339-44.

4. Coumel P, Fidelle J, Lucet V, Attuel PB. Catecholaminergic-induced severe ventricular arrhythmias with adams-stokes syndrome in children: report of four cases. Br Heart J. 1978 40:28-37.

5. Leenhardt A, Lucet V, Denjoy I, Grau F, Ngoc DD, Coumel P, et al. Catecholaminergic polymorphic ventricular tachycardia in children. A 7-year follow-up of 21 patients. Circulation. 1995; 91:1512-9

6. Priori SG, Napolitano C, Tiso N, Memmi M, Vignati G, Bloise R, et al. Mutations in the cardiac ryanodine receptor gene (hRyR2) underlie catecholaminergic polymorphic ventricular tachycardia. Circulation. 2001;103:196-200.

7. Laitinen PJ, Brown KM, Piippo K, Swan H, Devaney JM, Brahmbhatt $B$, et al. Mutations of the cardiac ryanodine receptor (RyR2) gene in familial polymorphic ventricular tachycardia. Circulation. 2001;103:485-90.

8. Landstrom AP, Dobrev D, Wehrens $\mathrm{XH}$. Calcium signaling and cardiac arrhythmias. Circ Res. 2017;120:1969-93. 
9. Roston TM, Van Petegem F, Sanatani S. Catecholaminergic polymorphic ventricular tachycardia: a model for genotype-specific therapy. Curr Opin Cardiol. 2017;32:78-85.

10. Cano-Hernández KS, Nava-Townsend S, Sánchez-Boiso A, Sánchez-Urbina R, Contreras-Ramos A, Erdmenger-Orellana JR, et al. Prevalence and spectrum of diseases that predispose to sudden cardiac death in Mexican children: a sample obtained from the federico gomez children's hospital of Mexico. Arch Cardiol Mex. 2018;88:268-76

11. Obeyesekere MN, Antzelevitch C, Krahn AD. Management of ventricular arrhythmias in suspected channelopathies. Circ Arrhythm Electrophysiol. 2015;8:221-31.

12. Priori SG, Napolitano C, Memmi M, Colombi B, Drago F, Gasparini $\mathrm{M}$, et al. Clinical and molecular characterization of patients with catecholaminergic polymorphic ventricular tachycardia. Circulation. 2002;106:69-74.

13. Priori SG, Wilde AA, Horie M, Cho Y, Behr ER, Berul C, et al. HRS/ EHRA/APHRS expert consensus statement on the diagnosis and management of patients with inherited primary arrhythmia syndromes: document endorsed by HRS, EHRA, and APHRS in may 2013 and by ACCF, AHA, PACES, and AEPC in june 2013. Heart Rhythm. 2013;10:1932-63.

14. Hayashi M, Denjoy I, Extramiana F, Maltret A, Buisson NR, Lupoglazoff JM, et al. Incidence and risk factors of arrhythmic events in catecholaminergic polymorphic ventricular tachycardia. Circulation. 2009;119:2426-34

15. Roston TM, Vinocur JM, Maginot KR, Mohammed S, Salerno JC, Etheridge SP, et al. Catecholaminergic polymorphic ventricular tachycardia in children: analysis of therapeutic strategies and outcomes from an international multicenter registry. Circ Arrhythm Electrophysiol. 2015;8:633-42.

16. Richter S, Gebauer R, Hindricks G, Brugada P. A classic electrocardiographic manifestation of catecholaminergic polymorphic ventricular tachycardia. J Cardiovasc Electrophysiol. 2012; 23:560.

17. Bhuiyan ZA, van den Berg MP, van Tintelen JP, Bink-Boelkens MT, Wiesfeld AC, Alders M, et al. Expanding spectrum of human RYR2-related disease: new electrocardiographic, structural, and genetic features. Circulation. 2007;116:1569-76.

18. Lahat H, Eldar M, Levy-Nissenbaum E, Bahan T, Friedman E, Khoury A, et al. Autosomal recessive catecholamine-or exerciseinduced polymorphic ventricular tachycardia: clinical features and assignment of the disease gene to chromosome 1p13-21. Circulation. 2001;103:2822-7.

19. Ringer S. A further contribution regarding the influence of the different constituents of the blood on the contraction of the heart. J Physiol. 1883;4:29-42.

20. Bers DM. Cardiac excitation-contraction coupling. Nature. 2002; 415:198-205.

21. Negretti N, O'Neill SC, Eisner DA. The effects of inhibitors of sarcoplasmic reticulum function on the systolic ca2+ transient in rat ventricular myocytes. J Physiol. 1993;468:35-52.

22. Sobie EA, Guatimosim S, Gómez-Viquez L, Song LS, Hartmann $H$, Saleet Jafri M, et al. The ca $2+$ leak paradox and rogue ryanodine receptors: SR ca $2+$ efflux theory and practice. Prog Biophys Mol Biol. 2006;90:172-85.

23. Zima AV, Bovo E, Bers DM, Blatter LA. $\mathrm{Ca}^{2}+$ spark-dependent and-independent sarcoplasmic reticulum $\mathrm{Ca}^{2}+$ leak in normal and failing rabbit ventricular myocytes. J Physiol. 2010;588:4743-57.

24. Guerrero-Hernández A, Ávila G, Rueda A. Ryanodine receptors as leak channels. Eur J Pharmacol. 2014;739:26-38.

25. Bers DM. Cardiac sarcoplasmic reticulum calcium leak: basis and roles in cardiac dysfunction. Annu Rev Physiol. 2014:76:107-27.

26. Otsu K, Willard HF, Khanna VK, Zorzato F, Green NM, MacLennan $\mathrm{DH}$, et al. Molecular cloning of cDNA encoding the ca2+ release channel (ryanodine receptor) of rabbit cardiac muscle sarcoplasmic reticulum. J Biol Chem. 1990;265:13472-83.

27. Fernandez-Velasco M, Gomez AM, Benitah JP, Neco P. Tachycardia. In: Yamada T, editor. Ryanodine Receptor Channelopathies: the New Kid in the Arrhythmia Neighborhood. Rijeka: InTech; 2012

28. Xiao Z, Guo W, Sun B, Hunt DJ, Wei J, Liu Y, et al. Enhanced cytosolic ca2+ activation underlies a common defect of central domain cardiac ryanodine receptor mutations linked to arrhythmias. J Biol Chem. 2016;291:24528-37.

29. Peng W, Shen H, Wu J, Guo W, Pan X, Wang R, et al. Structural basis for the gating mechanism of the Type 2 ryanodine receptor ryR2. Science. 2016;354:aah5324.

30. Leenhardt A, Denjoy I, Guicheney P. Catecholaminergic polymorphic ventricular tachycardia. Circ Arrhythm Electrophysiol. 2012;5:1044-52.
31. Zhao YT, Valdivia CR, Gurrola GB, Hernández JJ, Valdivia HH. Arrhythmogenic mechanisms in ryanodine receptor channelopathies. Sci China Life Sci. 2015;58:54-8.

32. Eisner DA, Kashimura T, Venetucci LA, Trafford AW. From the ryanodine receptor to cardiac arrhythmias. Circ J. 2009;73: $1561-7$

33. Kashimura T, Briston SJ, Trafford AW, Napolitano C, Priori SG, Eisner DA, et al. In the ryR2(R4496C) mouse model of CPVT, $\beta$-adrenergic stimulation induces ca waves by increasing SR ca content and not by decreasing the threshold for ca waves. Circ Res. 2010:107:1483-9.

34. Cerrone M, Colombi B, Santoro M, di Barletta MR, Scelsi M, Villani L, et al. Bidirectional ventricular tachycardia and fibrillation elicited in a knock-in mouse model carrier of a mutation in the cardiac ryanodine receptor. Circ Res. 2005;96:e77-82

35. Fernández-Velasco M, Rueda A, Rizzi N, Benitah JP, Colombi B, Napolitano C, et al. Increased ca2+ sensitivity of the ryanodine receptor mutant ryR2R4496C underlies catecholaminergic polymorphic ventricular tachycardia. Circ Res. 2009;104:201-9.

36. Jiang $D$, Chen W, Wang R, Zhang L, Chen SR. Loss of luminal $\mathrm{ca} 2+$ activation in the cardiac ryanodine receptor is associated with ventricular fibrillation and sudden death. Proc Natl Acad Sci U S A. 2007;104:18309-14.

37. Zhao YT, Valdivia CR, Gurrola GB, Powers PP, Willis BC, Moss RL, et al. Arrhythmogenesis in a catecholaminergic polymorphic ventricular tachycardia mutation that depresses ryanodine receptor function. Proc Natl Acad Sci U S A. 2015;112:E1669-77.

38. Roston TM, Guo W, Krahn AD, Wang R, Van Petegem F, Sanatani $\mathrm{S}$, et al. A novel RYR2 loss-of-function mutation (14855M) is associated with left ventricular non-compaction and atypical catecholaminergic polymorphic ventricular tachycardia. J Electrocardiol. 2017:50:227-33.

39. Fujii Y, Itoh H, Ohno S, Murayama T, Kurebayashi N, Aoki H, et al. A Type 2 ryanodine receptor variant associated with reduced $\mathrm{Ca} 2+$ release and short-coupled torsades de pointes ventricular arrhythmia. Heart Rhythm. 2017;14:98-107.

40. des Georges A, Clarke OB, Zalk R, Yuan Q, Condon KJ, Grassucci RA, et al. Structural basis for gating and activation of ryR1. Cell. 2016:167:145-57e17.

41. Dulhunty AF, Wium E, Li L, Hanna AD, Mirza S, Talukder S, et al. Proteins within the intracellular calcium store determine cardiac ryR channel activity and cardiac output. Clin Exp Pharmacol Physiol. 2012;39:477-84

42. Scriven DR, Asghari P, Moore ED. Microarchitecture of the dyad. Cardiovasc Res. 2013;98:169-76.

43. Roux-Buisson N, Cacheux M, Fourest-Lieuvin A, Fauconnier J, Brocard J, Denjoy I, et al. Absence of triadin, a protein of the calcium release complex, is responsible for cardiac arrhythmia with sudden death in human. Hum Mol Genet. 2012:21:2759-67.

44. Nyegaard M, Overgaard MT, Søndergaard MT, Vranas M, Behr ER, Hildebrandt LL, et al. Mutations in calmodulin cause ventricular tachycardia and sudden cardiac death. Am J Hum Genet. 2012:91:703-12.

45. Gomez-Hurtado N, Boczek NJ, Kryshtal DO, Johnson CN, Sun J, Nitu FR, et al. Novel CPVT-associated calmodulin mutation in CALM3 (CALM3-A103V) activates arrhythmogenic ca waves and sparks. Circ Arrhythm Electrophysiol. 2016;9:e004161.

46. Rizzi N, Liu N, Napolitano C, Nori A, Turcato F, Colombi B, et al. Unexpected structural and functional consequences of the R330 homozygous mutation in cardiac calsequestrin: a complex arrhythmogenic cascade in a knock in mouse model. Circ Res. 2008;103:298-306

47. Rooryck C, Kyndt F, Bozon D, Roux-Buisson N, Sacher F. Probst $V$, et al. New family with catecholaminergic polymorphic ventricular tachycardia linked to the triadin gene. J Cardiovasc Electrophysiol. 2015;26:1146-50.

48. Postma AV, Denjoy I, Hoorntje TM, Lupoglazoff JM, Da Costa A Sebillon $\mathrm{P}$, et al. Absence of calsequestrin 2 causes severe forms of catecholaminergic polymorphic ventricular tachycardia. Circ Res. 2002:91:e21-6.

49. Knollmann BC, Chopra N, Hlaing T, Akin B, Yang T, Ettensohn K, et al. Casq2 deletion causes sarcoplasmic reticulum volume increase, premature ca $2+$ release, and catecholaminergic polymorphic ventricular tachycardia. J Clin Invest. 2006:116:2510-20.

50. Denegri M, Avelino-Cruz JE, Boncompagni S, De Simone SA, Auricchio A, Villani L, et al. Viral gene transfer rescues arrhythmogenic phenotype and ultrastructural abnormalities in adult calsequestrin-null mice with inherited arrhythmias. Circ Res. 2012;110:663-8

51. Denegri M, Bongianino R, Lodola F, Boncompagni S, De Giusti VC, Avelino-Cruz JE, et al. Single delivery of an adeno-associat- 
ed viral construct to transfer the CASQ2 gene to knock-in mice affected by catecholaminergic polymorphic ventricular tachycardia is able to cure the disease from birth to advanced age. Circulation. 2014:129:2673-81.

52. Chopra N, Yang T, Asghari P, Moore ED, Huke S, Akin B, et al. Ablation of triadin causes loss of cardiac ca2+ release units, impaired excitation-contraction coupling, and cardiac arrhythmias. Proc Natl Acad Sci U S A. 2009;106:7636-41.

53. Chopra N, Knollmann BC. Triadin regulates cardiac muscle couplon structure and microdomain $\mathrm{ca}(2+)$ signalling: a path towards ventricular arrhythmias. Cardiovasc Res. 2013;98: 187-91.

54. Song L, Alcalai R, Arad M, Wolf CM, Toka O, Conner DA, et al. Calsequestrin 2 (CASQ2) mutations increase expression of calreticulin and ryanodine receptors, causing catecholaminergic polymorphic ventricular tachycardia. J Clin Invest. 2007; 117:1814-23.

55. Devalla HD, Gélinas R, Aburawi EH, Beqqali A, Goyette P, Freund $C$, et al. TECRL, a new life-threatening inherited arrhythmia gene associated with overlapping clinical features of both LQTS and CPVT. EMBO Mol Med. 2016;8:1390-408.

56. Bhuiyan ZA, Hamdan MA, Shamsi ET, Postma AV, Mannens MM Wilde AA, et al. A novel early onset lethal form of catecholaminergic polymorphic ventricular tachycardia maps to chromosome 7p14-p22. J Cardiovasc Electrophysiol. 2007:18:1060-6.

57. Pastore F, Parisi V, Romano R, Rengo G, Pagano G, Komici K, et al. Genetic test for dilated and hypertrophic cardiomyopathies: useful or less than useful for patients? Transl Med UniSa. 2013;5:14-7.

58. Spoonamore KG, Johnson NM. Who pays? Coverage challenges for cardiovascular genetic testing in U.S. Patients. Front Cardiovasc Med. 2016:3:14.

59. Jensen $H H$, Brohus $M$, Nyegaard M, Overgaard MT. Human calmodulin mutations. Front Mol Neurosci. 2018;11:396

60. Lahat H, Pras E, Olender T, Avidan N, Ben-Asher E, Man O, et al. A missense mutation in a highly conserved region of CASQ2 is associated with autosomal recessive catecholamine-induced polymorphic ventricular tachycardia in bedouin families from israel. Am J Hum Genet. 2001:69:1378-84.

61. Lahrouchi N, Behr ER, Bezzina CR. Next-generation sequencing in post-mortem genetic testing of young sudden cardiac death cases. Front Cardiovasc Med. 2016;3:13.

62. Pérez-Riera AR, Barbosa-Barros R, de Rezende Barbosa MP, Daminello-Raimundo R, de Lucca AA Jr., de Abreu LC, et al. Catecholaminergic polymorphic ventricular tachycardia, an update. Ann Noninvasive Electrocardiol. 2018:23:e12512.

63. Perry MD, Vandenberg JI. TECRL: connecting sequence to consequence for a new sudden cardiac death gene. EMBO Mol Med. 2016:8:1364-5

64. McNally EM, Puckelwartz MJ. Genetic variation in cardiomyopathy and cardiovascular disorders. Circ J. 2015;79:1409-15.

65. Shampo MA, Kyle RA. Kary B. Mullis-nobel laureate for procedure to replicate DNA. Mayo Clin Proc. 2002;77:606.

66. Sanger F, Nicklen S, Coulson AR. DNA sequencing with chainterminating inhibitors. Proc Natl Acad Sci U S A. 1977;74: 5463-7.

67. Thouvenot $P$, Ben Yamin B, Fourrière $L$, Lescure $A$, Boudier $T$, Del Nery $E$, et al. Functional assessment of genetic variants with outcomes adapted to clinical decision-making. PLoS Genet. 2016;12:e1006096.

68. Totomoch-Serra A, Marquez MF, Cervantes-Barragán DE. Sanger sequencing as a first-line approach for molecular diagnosis of andersen-tawil syndrome. F1000Res. 2017:6:1016.

69. Ackerman MJ, Priori SG, Willems S, Berul C, Brugada R, Calkins $\mathrm{H}$, et al. HRS/EHRA expert consensus statement on the state of genetic testing for the channelopathies and cardiomyopathies: this document was developed as a partnership between the heart rhythm society (HRS) and the European heart rhythm association (EHRA). Europace. 2011;13:1077-109.
70. Alonso-Ortiz N, Gallegos-Cortez A, Antunes-Argüelles E, Villarreal-Molina $\mathrm{T}$, Totomoch-Serra A, Iturralde-Torres $\mathrm{P}$, et al. Catecholaminergic polymorphic ventricular tachycardia due to de novo RyR2 mutation: recreative cycling as a trigger of lethal arrhythmias. Arch Med Sci. 2019;15 [In press].

71. Tristani-Firouzi M, Jensen JL, Donaldson MR, Sansone V, Meola $G$. Hahn A et al. Functional and clinical characterization of KCNJ2 mutations associated with LQT7 (Andersen syndrome). J Clin Invest. 2002;110:381-8.

72. Inoue YY, Aiba T, Kawata H, Sakaguchi T, Mitsuma W, Morita H, et al. Different responses to exercise between andersen-tawil syndrome and catecholaminergic polymorphic ventricular tachycardia. Europace. 2018;20:1675-82.

73. Márquez MF, Totomoch-Serra A Burgoa JA, Méndez A, GómezFlores JR, Nava S, et al. Abnormal electroencephalogram, epileptic seizures, structural congenital heart disease and aborted sudden cardiac death in andersen-tawil syndrome. Int J Cardiol. 2015:180:206-9.

74. Tully I, Atherton J, Hunt L, Ingles J, Semsarian C, McGaughran J, et al. Rarity and phenotypic heterogeneity provide challenges in the diagnosis of andersen-tawil syndrome: two cases presenting with ECGs mimicking catecholaminergic polymorphic ventricular tachycardia (CPVT). Int J Cardiol. 2015;201:473-5.

75. Mohler PJ, Splawski I, Napolitano C, Bottelli G, Sharpe L, Timothy $\mathrm{K}$, et al. A cardiac arrhythmia syndrome caused by loss of ankyrin-B function. Proc Natl Acad Sci U S A. 2004;101:9137-42.

76. Epstein AE, DiMarco JP, Ellenbogen KA, Estes NA, Freedman RA, Gettes LS, et al. ACC/AHA/HRS 2008 guidelines for device-based therapy of cardiac rhythm abnormalities: a report of the American college of cardiology/American heart association task force on practice guidelines (Writing committee to revise the ACC/ AHA/NASPE 2002 guideline update for implantation of cardiac pacemakers and antiarrhythmia devices): developed in collaboration with the American association for thoracic surgery and society of thoracic surgeons. Circulation. 2008:117:e350-408.

77. Van der Werf C, Zwinderman AH, Wilde AA. Therapeutic approach for patients with catecholaminergic polymorphic ventricular tachycardia: state of the art and future developments. Europace. 2012:14:175-83

78. Watanabe H, van der Werf C, Roses-Noguer F, Adler A, Sumitomo N, Veltmann C, et al. Effects of flecainide on exercise-induced ventricular arrhythmias and recurrences in genotypenegative patients with catecholaminergic polymorphic ventricular tachycardia. Heart Rhythm. 2013;10:542-7.

79. Watanabe H, Chopra N, Laver D, Hwang HS, Davies SS, Roach $\mathrm{DE}$, et al. Flecainide prevents catecholaminergic polymorphic ventricular tachycardia in mice and humans. Nat Med. 2009, 15:380-3.

80. Khoury A, Marai I, Suleiman M, Blich M, Lorber A, Gepstein L, et al. Flecainide therapy suppresses exercise-induced ventricular arrhythmias in patients with CASQ2-associated catecholaminergic polymorphic ventricular tachycardia. Heart Rhythm. 2013. $10 \cdot 1671-5$

81. Miyake CY, Webster G, Czosek RJ, Kantoch MJ, Dubin AM, Avasarala K, et al. Efficacy of implantable cardioverter defibrillators in young patients with catecholaminergic polymorphic ventricular tachycardia: success depends on substrate. Circ Arrhythm Electrophysiol. 2013;6:579-87.

82. Wilde AA, Bhuiyan ZA, Crotti L, Facchini M, De Ferrari GM, Paul $T$, et al. Left cardiac sympathetic denervation for catecholaminergic polymorphic ventricular tachycardia. N Engl J Med. 2008; 358:2024-9.

83. De Ferrari GM, Dusi V, Spazzolini C, Bos JM, Abrams DJ, Berul $\mathrm{Cl}$, et al. Clinical management of catecholaminergic polymorphic ventricular tachycardia: the role of left cardiac sympathetic denervation. Circulation. 2015;131:2185-93.

84. Liu W, Xie Y, Ma J, Luo X, Nie P, Zuo Z, et al. IBS: an illustrator for the presentation and visualization of biological sequences. Bioinformatics. 2015;31:3359-61. 